Supplement of Geosci. Model Dev., 13, 2393-2431, 2020

https://doi.org/10.5194/gmd-13-2393-2020-supplement

C Author(s) 2020. This work is distributed under

the Creative Commons Attribution 4.0 License.

(c) (1)

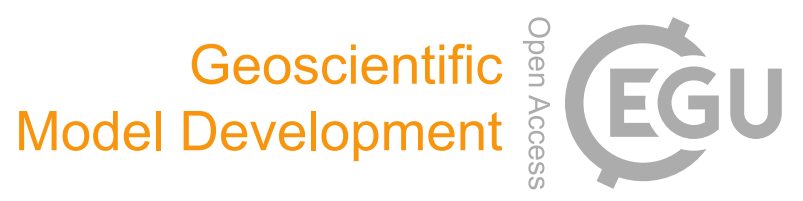

Supplement of

\title{
Ocean biogeochemistry in the Norwegian Earth System Model version 2 (NorESM2)
}

Jerry F. Tjiputra et al.

Correspondence to: Jerry F. Tjiputra (jerry.tjiputra@norceresearch.no)

The copyright of individual parts of the supplement might differ from the CC BY 4.0 License. 


\section{Content descriptions}

This document contains additional plots in support of the main manuscript submitted to Geoscientific Model Development. Figure S1 depicts quasi-conservative climatological PO (phosphate-oxygen) tracer for the Atlantic section from observations and several versions of NorESM models. Figures S2 and S3 depict climatological temperature and salinity distributions at the surface and across vertical sections of Atlantic and Pacific, as simulated by the NorESM2-LM model. Differences between NorESM2-LM and observations are also shown.

Figure S4 shows climatological mixed layer depths for different seasons from NorESM2-LM and observations. Figure S5 shows CFC-11 tracer concentration across vertical sections of Atlantic and Pacific from NorESM2-LM and observations. Figures S6 and S7 are similar to Fig. S2, but for phosphate and dissolved inorganic carbon simulated by the stand-alone ocean component of NorESM2 (NorESM2-OC; see also Section 4 of the main manuscript).

\footnotetext{
${ }^{*}$ Corresponding author
}

Email: jerry.tjiputra@norceresearch.no 


\section{Figures}

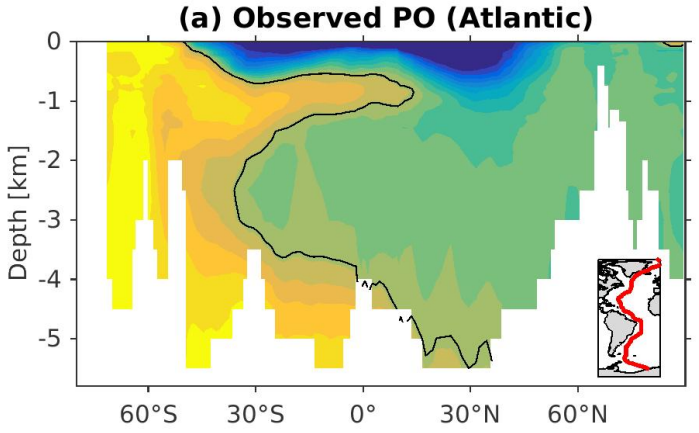

(c) NorESM2-LM PO (Atlantic)

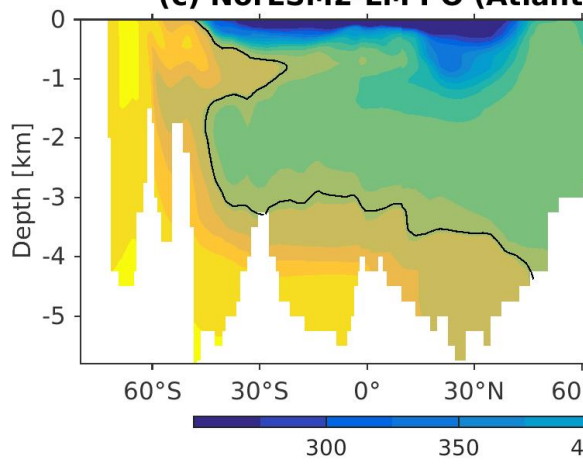

(b) NorESM1-ME PO (Atlantic)

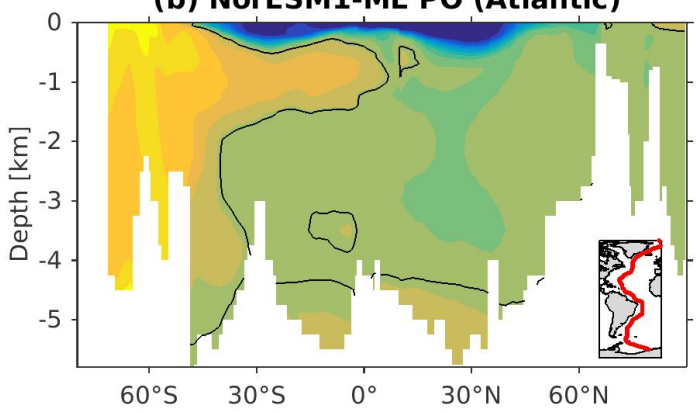

(d) NorESM2-MM PO (Atlantic)

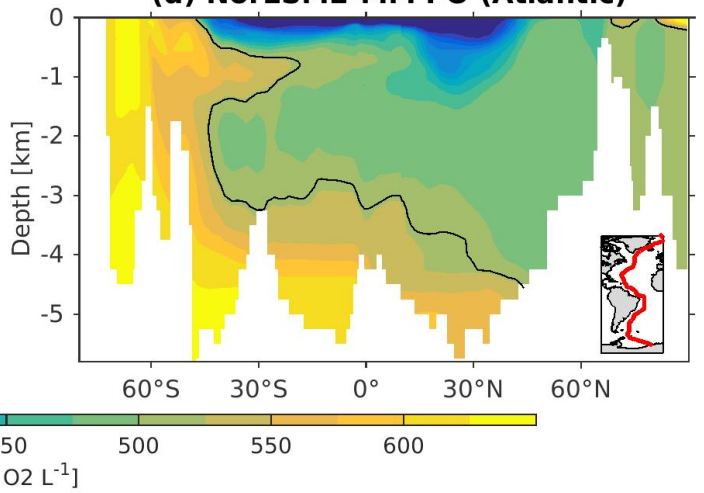

Supplemental Figure S1. Atlantic section plot of PO (phosphate-oxygen) tracer from observations and different NorESM model versions. Black contour lines depict values of $520 \mu \mathrm{mol} \mathrm{O}_{2}$ $\mathrm{L}^{-1}$, which approximately illustrate the boundary separating the northern source water and the southern source water in the interior. 
(a) Surface temperature

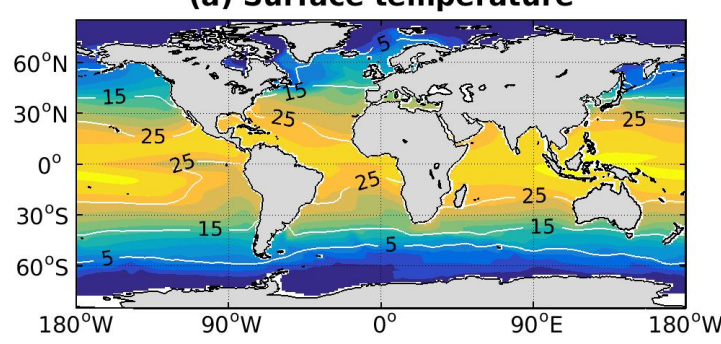

(b) Atlantic section

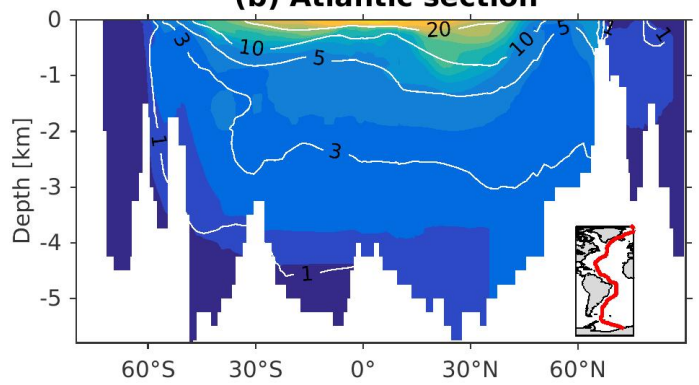

(c) Pacific section

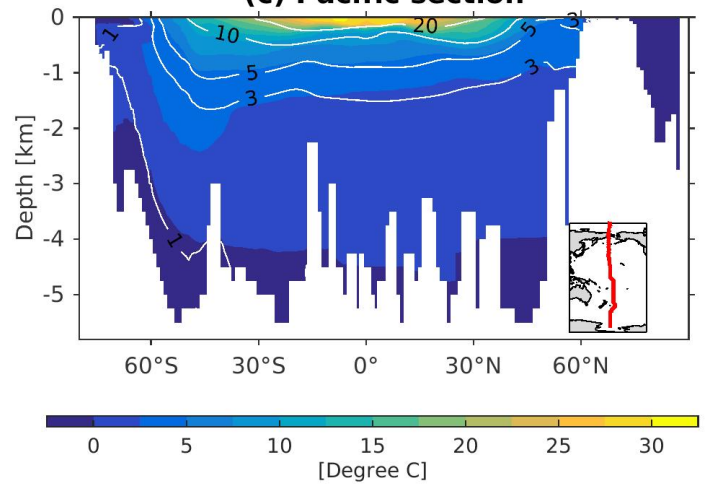

(d) NorESM-observation (surface)

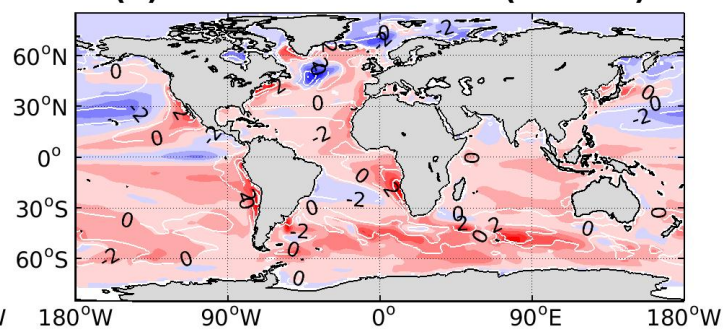

(e) NorESM-observation (Atlantic)

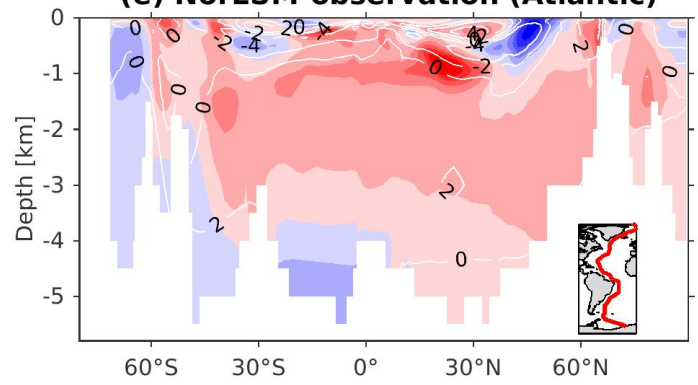

(f) NorESM-observation (Pacific)

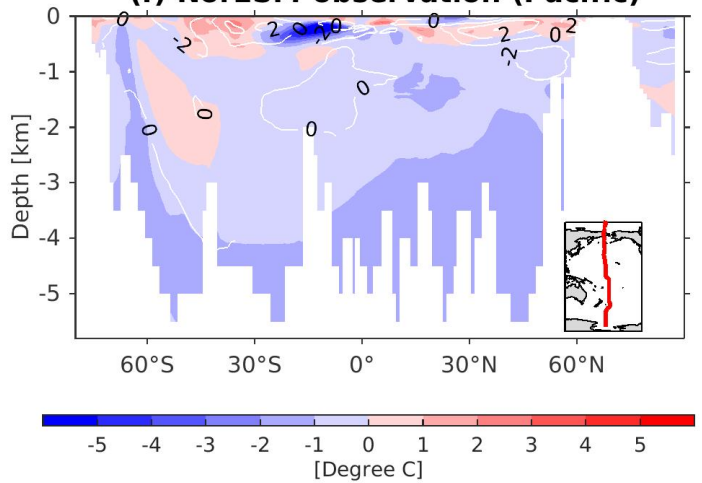

Supplemental Figure S2. Climatological temperature values at the (a) surface and across the vertical sections of (b) Atlantic and (c) Pacific from NorESM2-LM (color-shadings) and observations (contour lines). Differences between NorESM2-LM (NorESM1) and observations are shown in colorshadings (contour-lines) in panels (d)-(f). 
(a) Surface salinity

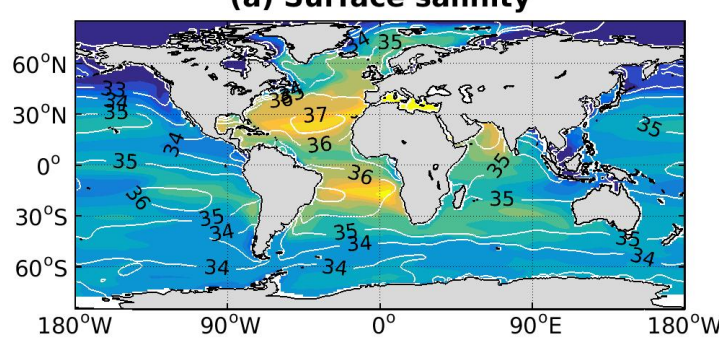

(b) Atlantic section

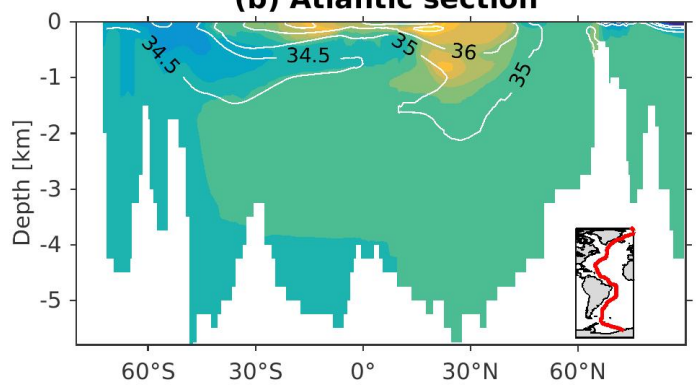

(c) Pacific section
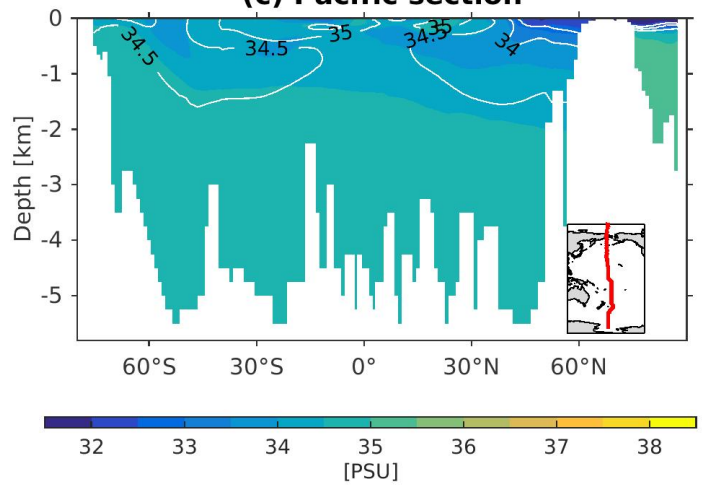

(d) NorESM-observation (surface)

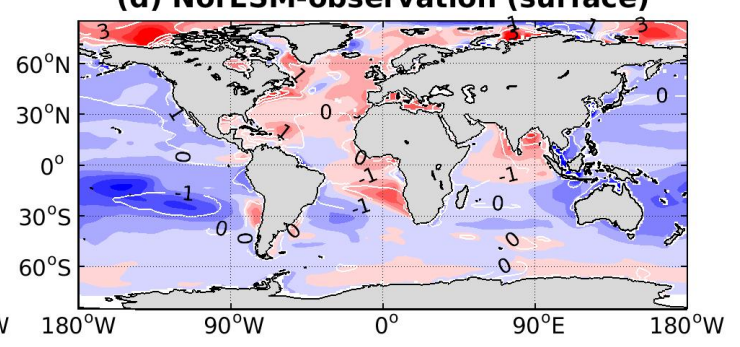

(e) NorESM-observation (Atlantic)

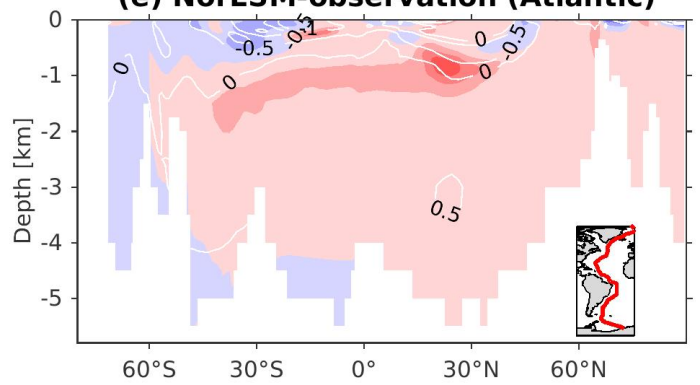

(f) NorESM-observation (Pacific)

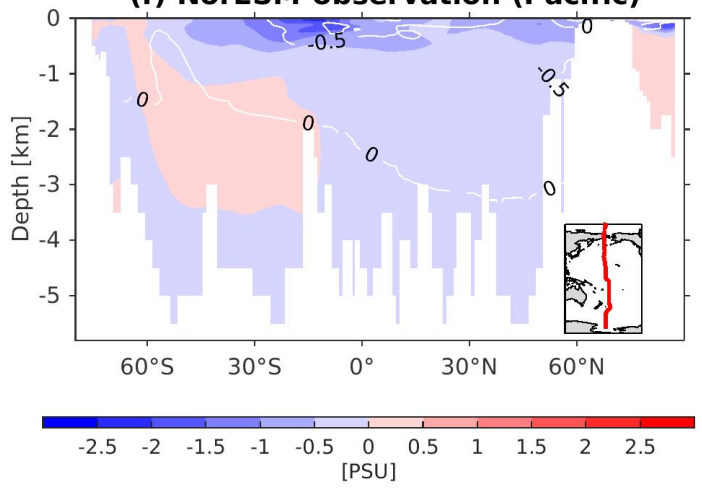

Supplemental Figure S3. Same as Fig. S2 but for salinity. 
(a) NorESM2-LM JFM MLD

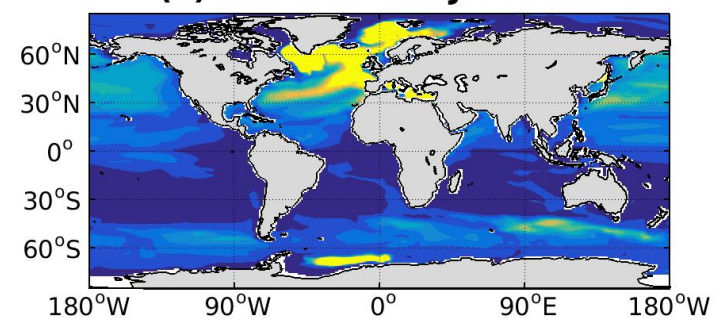

(b) NorESM2-LM AMJ MLD

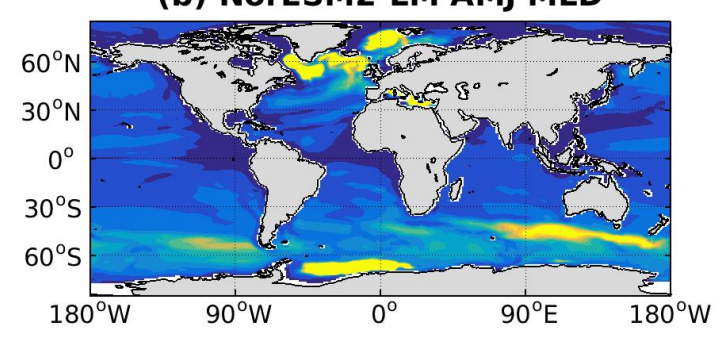

(c) NorESM2-LM JAS MLD

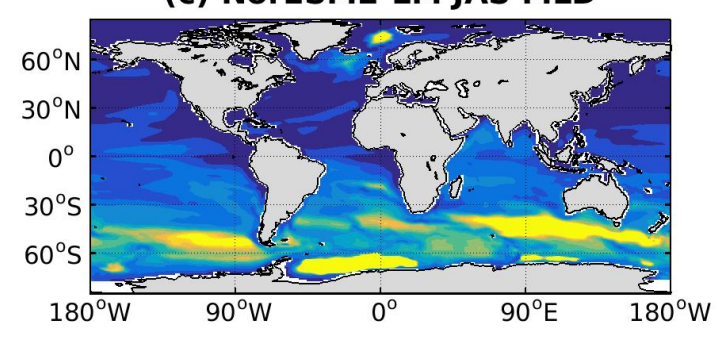

(d) NorESM2-LM OND MLD

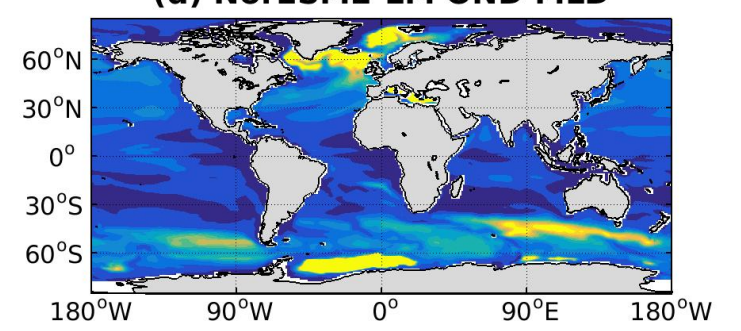

(e) Observed JFM MLD

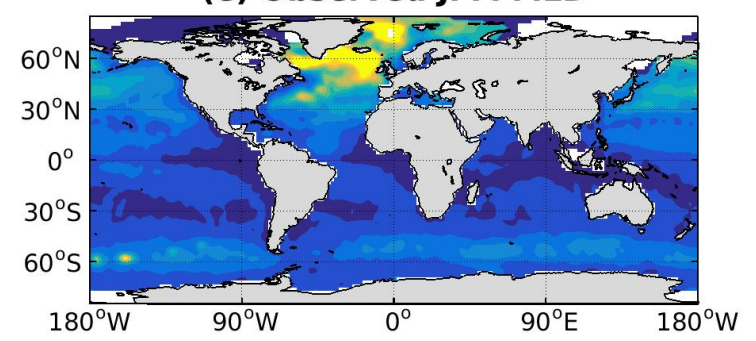

(f) Observed AMJ MLD

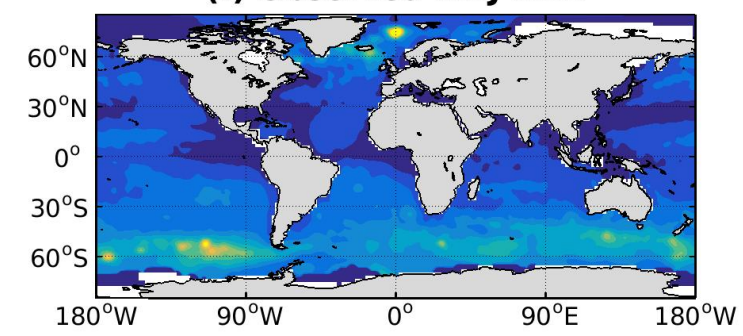

(g) Observed JAS MLD

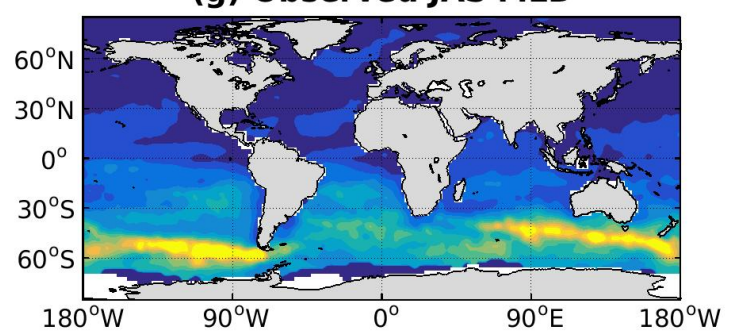

(h) Observed OND MLD

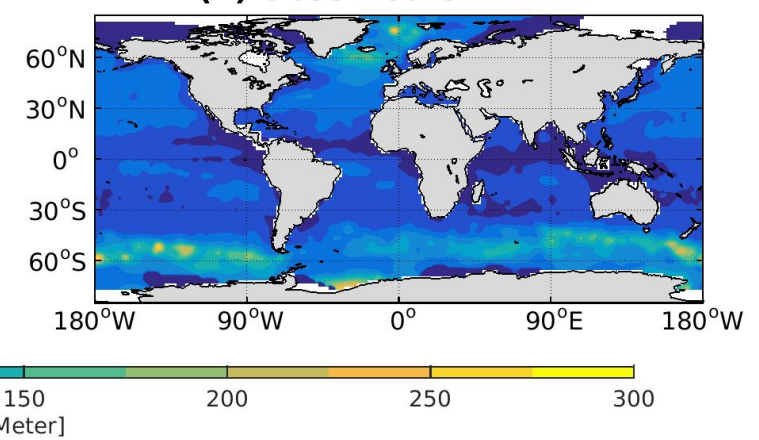

Supplemental Figure S4. Climatology of seasonal mixed layer depth as (left-column) simulated in NorESM2-LM and (right-column) estimated from from observations. 


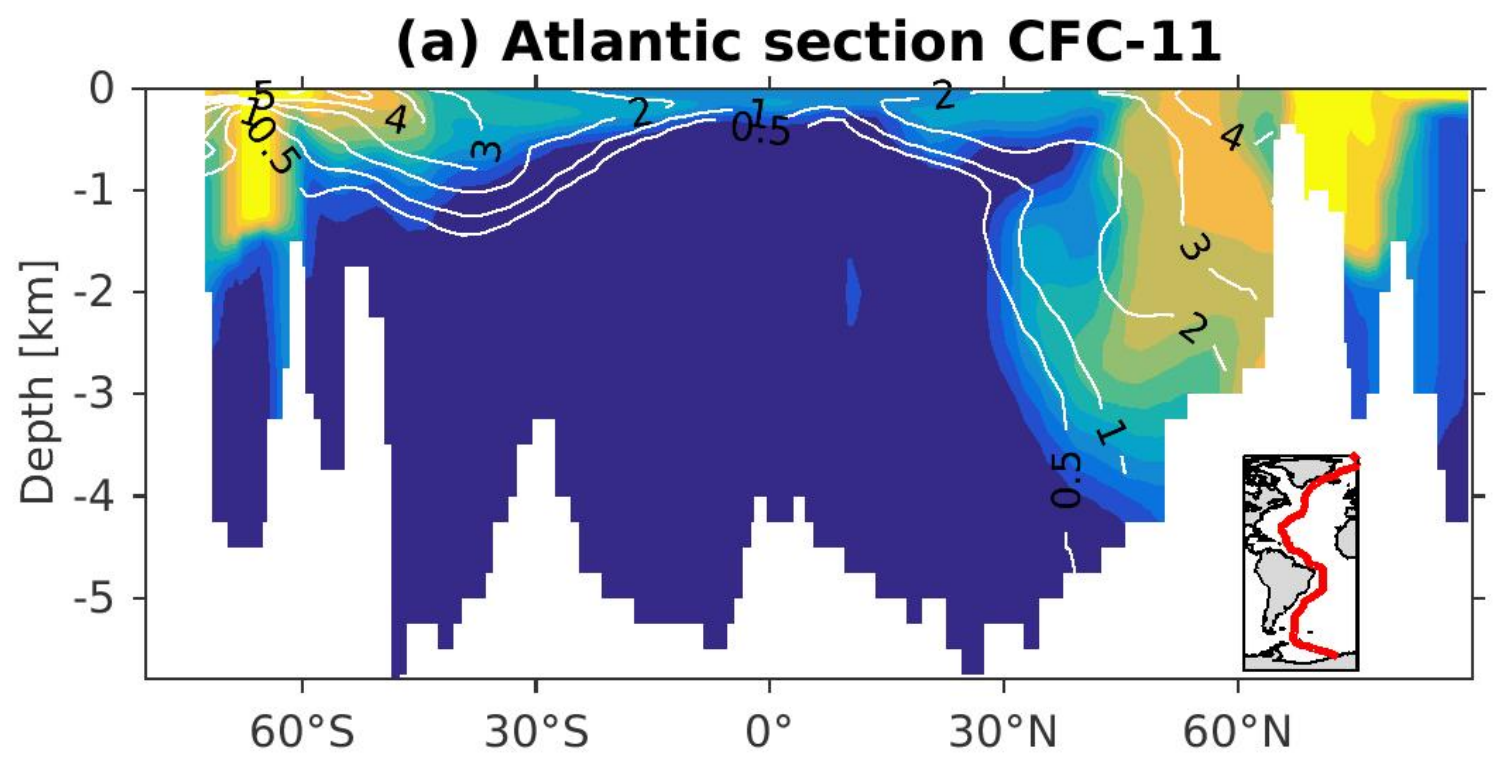

(b) Pacific section CFC-11

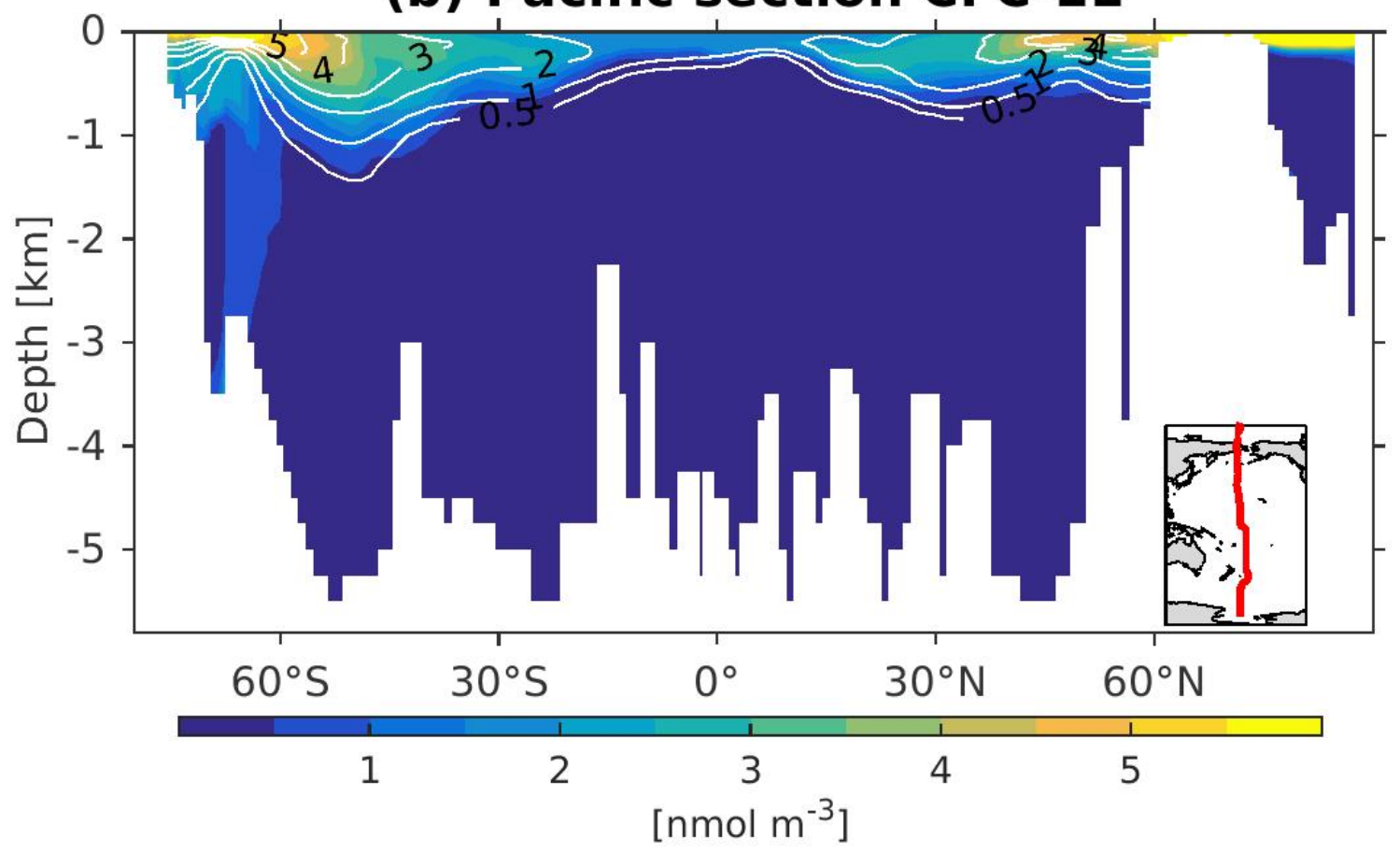

Supplemental Figure S5. Concentration of CFC-11 across the vertical sections of (a) Atlantic and (b) Pacific from NorESM2-LM (color-shadings) and observations (contour lines). 
(a) NorESM2-OC surface phosphate

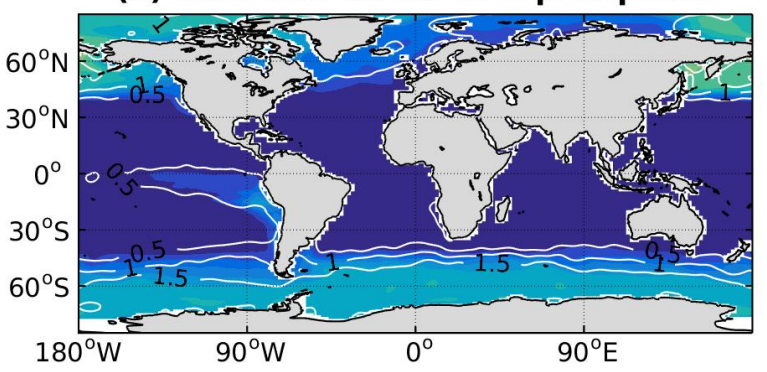

(b) NorESM2-OC Atlantic section phosphate

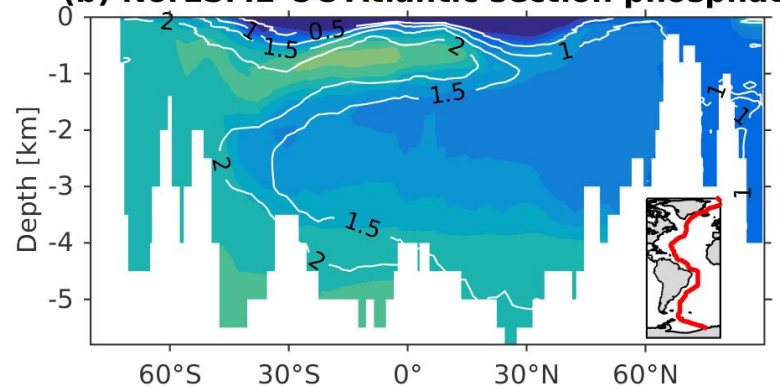

(c) NorESM2-OC Pacific section phosphate

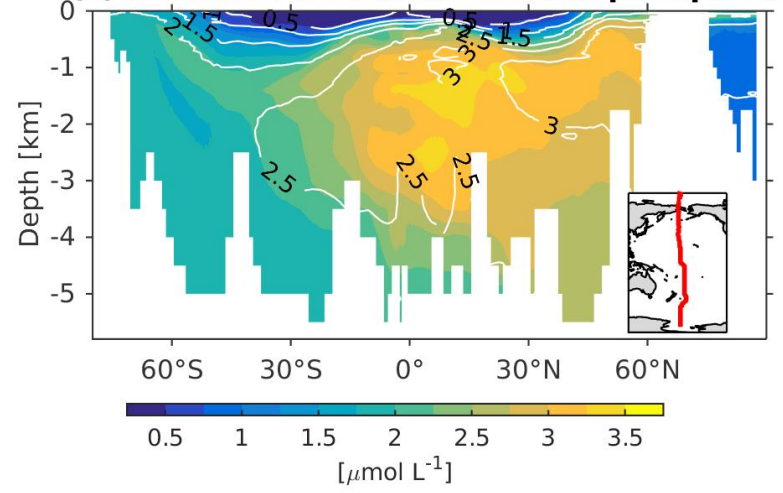

(d) NorESM2-OC - observation

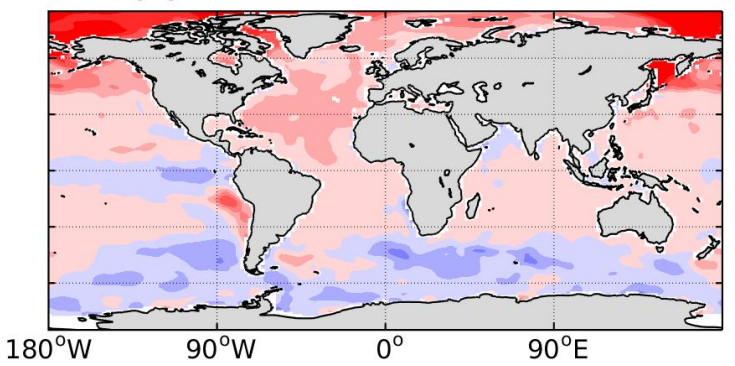

(e) NorESM2-OC - observation

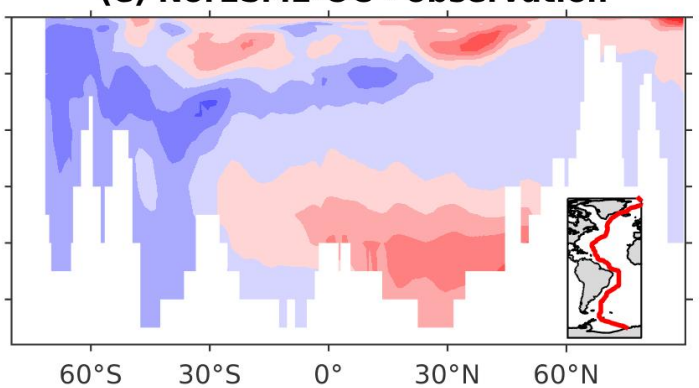

(f) NorESM2-OC - observation

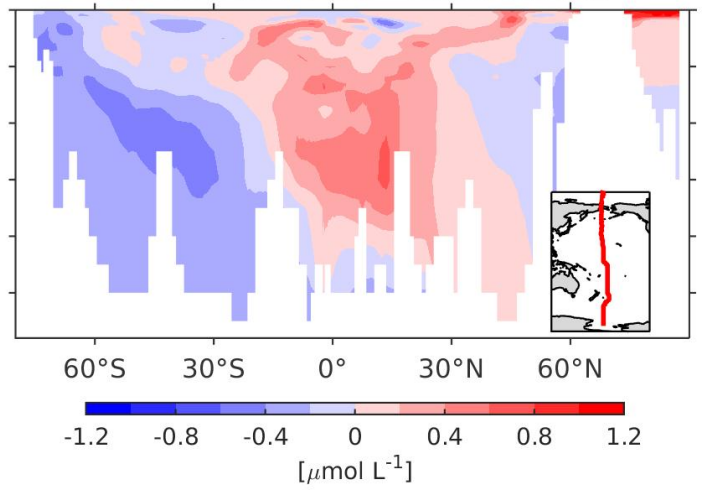

Supplemental Figure S6. Same as Fig. S2 but shown here are phosphate concentration as simulated by NorESM2-OC, which is a stand-alone ocean simulation forced by atmospheric CORE normal year forcing (see also Section 4 in the main manuscript). 
(a) NorESM2-OC surface DIC

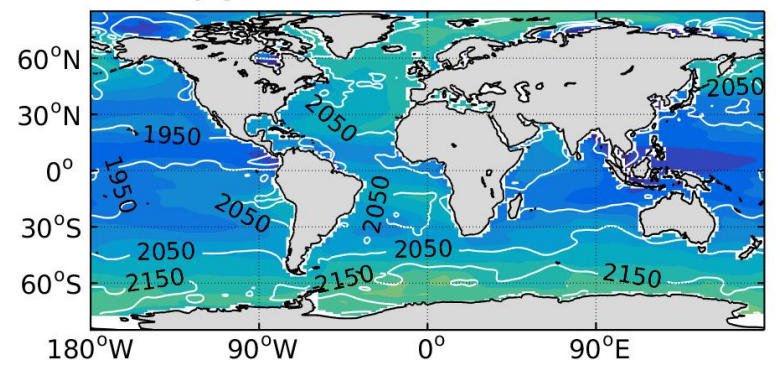

(b) NorESM2-OC Atlantic section DIC

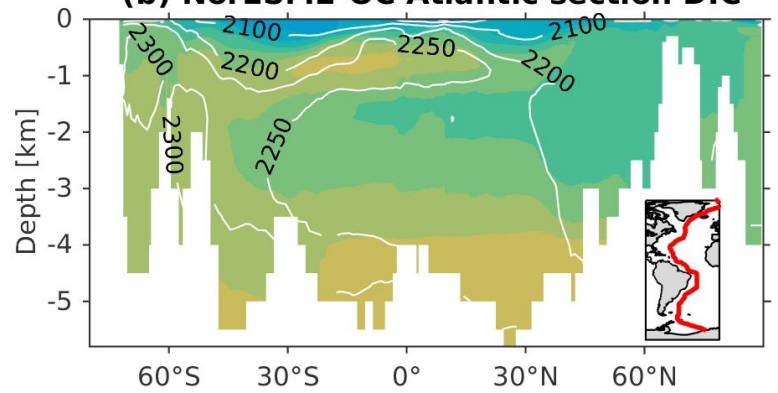

(c) NorESM2-OC Pacific section DIC

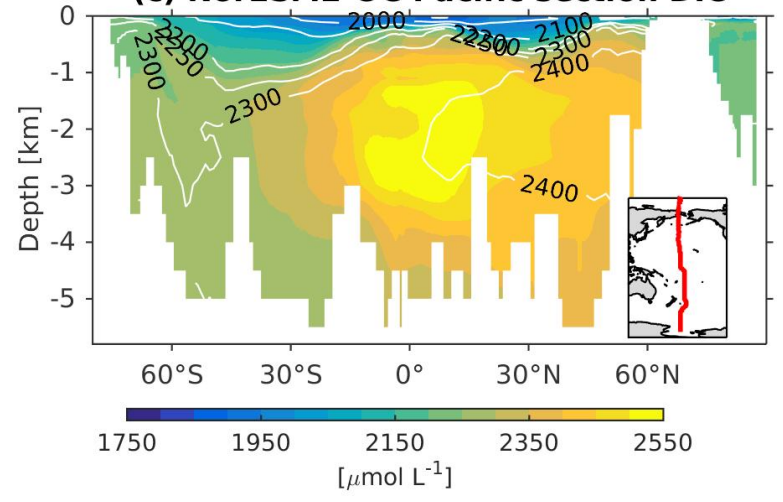

(d) NorESM2-OC - observation

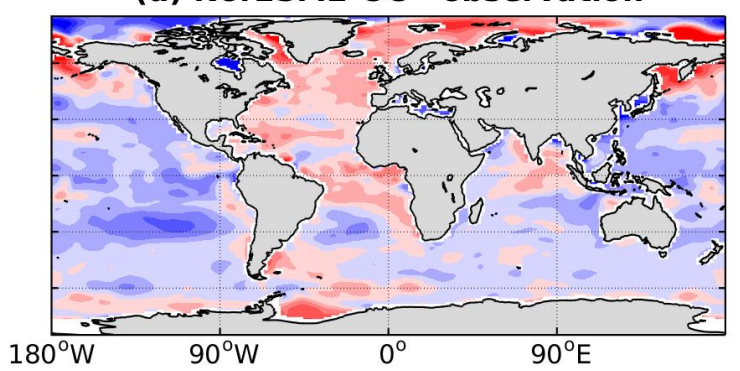

(e) NorESM2-OC - observation

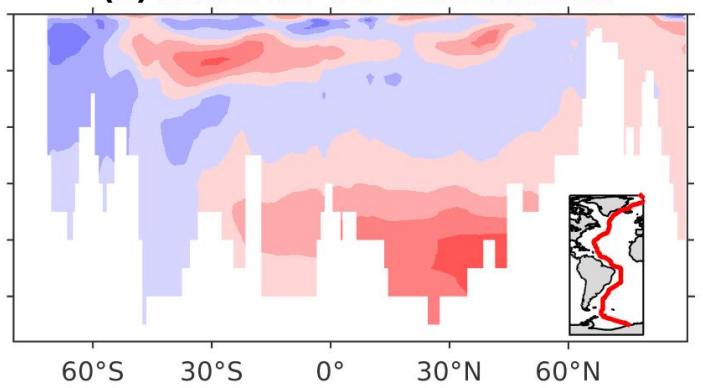

(f) NorESM2-OC - observation

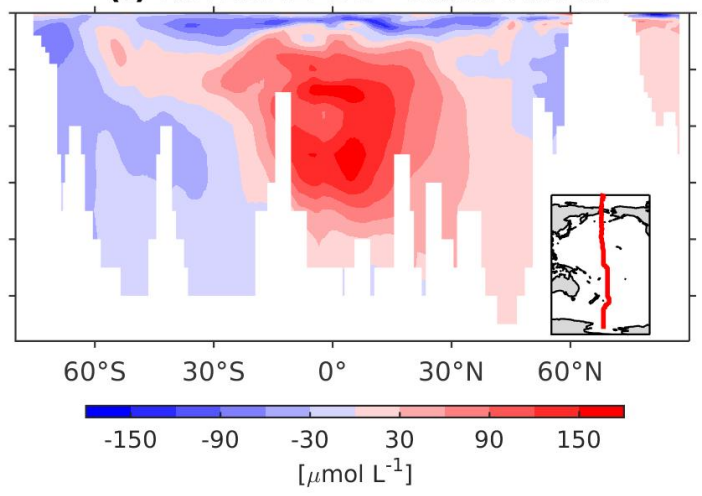

Supplemental Figure S7. Same as Fig. S2 but shown here are dissolved inorganic carbon concentration as simulated by NorESM2-OC, which is a stand-alone ocean simulation forced by atmospheric CORE normal year forcing (see also Section 4 in the main manuscript). 